\title{
Views and Perceptions of Local Council Partners Concerning a Regional-scale Health Promotion Initiative in Rural Australia
}

\author{
Quynh Lế ${ }^{1, *}$, Stuart Auckland ${ }^{1}$, Hoang Boi Nguyen ${ }^{1}$, Daniel R Terry ${ }^{1,2}$ \\ ${ }^{1}$ University of Tasmania, Australia \\ ${ }^{2}$ University of Melbourne, Australia \\ *Corresponding Author: Quynh.Le@utas.edu.au
}

Copyright (C) 2014 Horizon Research Publishing All rights reserved.

\begin{abstract}
There are a number of risk factors which increasingly impact the health and wellbeing of Australians, particularly in rural communities. To address the health and wellbeing of communities, local governments are taking on a more focused role by supporting healthy community initiatives (HCI). This paper presents local council partners perceptions concerning a regional-scale health promotion initiative that was undertaken in rural Tasmania, Australia. The evaluation provides insight into the future decisions and strategies that may be developed to improve processes, methods and outcomes of health initiatives undertaken by local governments. The study used a mixed methods approach collecting data through a questionnaire, focus group discussions and interviews with stakeholders and participating councils to provide an understanding of the effectiveness and success of, and barriers to, the health promotion initiative. It was found that there was an emphasis by local councils on programs that promoted physical activities, while programs that focused on healthy food and other health promotion topics, such as quit smoking and healthy workplaces were less emphasised. Overall, the health promotion initiative was perceived to be effective; however, there was little measureable evidence as to the outcomes of the various projects within the initiative and there was concern regarding the sustainability of the initiative beyond the funding timeframe. Community based, health promotion interventions are complex. Local government are suitably placed to deliver health promotion initiatives, as they have a greater understanding and can affect the greatest change by investing in projects with the highest priority among those communities within their boundaries. Nevertheless, sustainability of projects beyond funding allocation, while building and improving partnerships among local governments, and service agencies to pool resources and capture specific target groups must be central to ongoing initiatives.
\end{abstract}

Keywords Local Government, Health Promotion, Health Initiative, Physical Activity, Sustainability, Success, Barriers

\section{Introduction}

Australia has one of the highest life expectancies in the world; ranked fourth in 2009 [1]. On the other hand, there are a number of risk factors which are increasingly impacting on the health and wellbeing of Australians. For example alcohol consumption remains high, while obesity rates $(28 \%)$ and physical inactivity rates $(38 \%)$ have steadily risen. For example, since 2005 , there has been a $30 \%$ increase in obesity and a 5\% increase in physical inactivity [1-3]. These health risk factors impact the ever burgeoning number of non-communicable or chronic diseases [3], which include but are not limited to diabetes, cardiovascular and heart disease, cirrhosis, cancer and stroke. Reducing the incidence of these health risk factors in order to reduce this increasing disease burden, remains vital for national, state and local governments, however, there has been an increased shift toward health promotion and preventative strategies $[2,3]$.

Traditionally, a specialised field of practice focusing on preventative health care such as screening programs and health advice, health promotion has expanded to include individuals and communities as active partners in shaping the health process $[4,5]$. Health promotion activities are currently endorsed throughout the world in many shapes and forms. For instance, the Healthy Cities, Municipalities and Islands movement was initiated by the World Health Organization (WHO). It is a typical health promotion model, emphasising the role of local authorities in establishing optimal conditions for mutual support within communities to develop in areas such as health and well-being [6-10].

One such example of establishing optimal conditions to develop health and well-being of the community is the Health Promotion Initiatives project conducted by the Cradle Coast Authority (CCA). The CCA consists of nine member municipal council areas on the North West coast of Tasmania, an island state off the south of Australia, as shown in Figure 1. These member councils include Burnie City, Devonport City, Central Coast, Circular Head, Kentish, King Island, Latrobe, Waratah-Wynyard and West Coast. The CCA covers $22,520 \mathrm{~km}^{2}$ (roughly a third of the state) 
with a total population of 112,383 mainly concentrated on the northern coastal strip and in the urban centres of Burnie and Devonport [11]. The small population base and the remoteness of some of the councils can create challenges in the provision of core council services such as roads, rates and rubbish and experience financial constraints to provide additional services such as health promotion.

The region is reliant on agriculture, forestry, manufacturing, mining, retail and tourism [12,13] and has a high level of relative socio-economic disadvantage compared to other areas of Australia with a mean SEIFA index of 922, and a range of 887-953 (an index lower than 1000 is considered relative disadvantage) [14]. The level of long-term unemployment in Tasmania has been highest among the 15 to 44 age groups since the 1980s with the North West of Tasmania experiencing the highest levels of long-term unemployment over this time [15, 16]. The unemployment rates for the municipal councils in the North West were reported to be slightly above state levels $(5.6 \%)$ and national levels (5.1\%) [17].

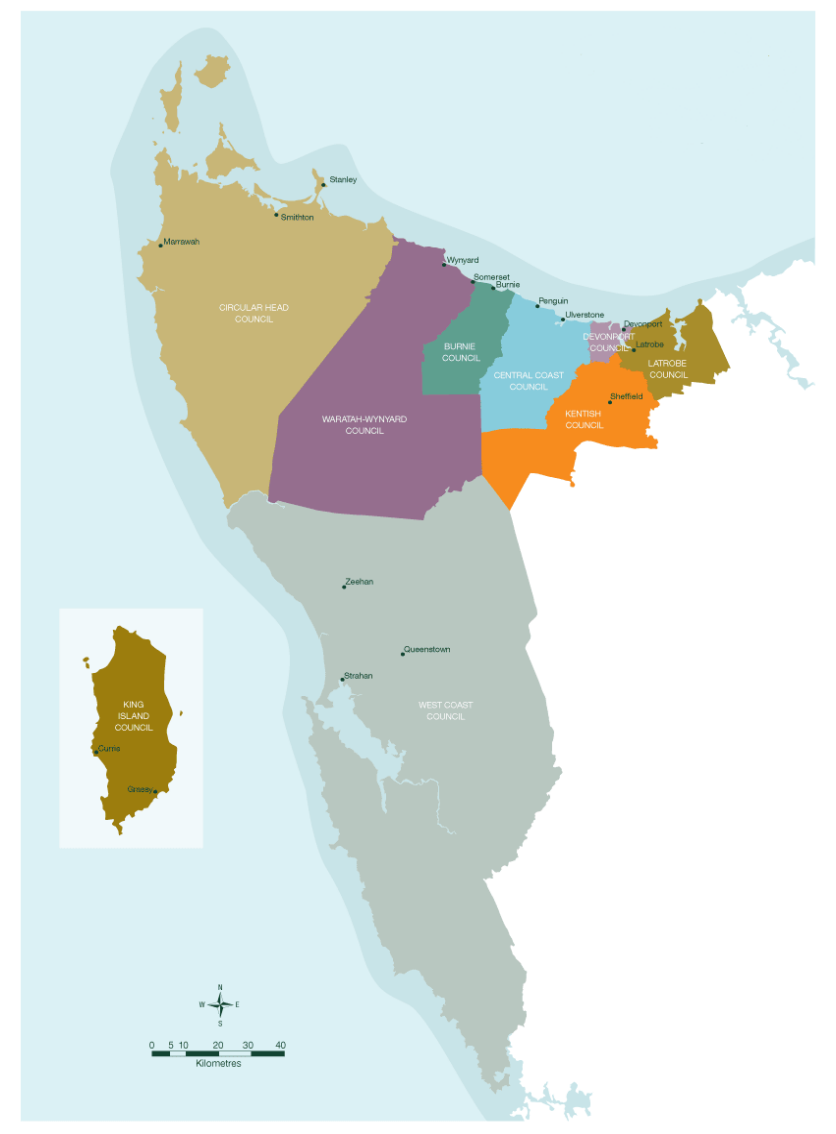

Figure 1. Municipalities encompassing the Cradle Coast Authority [12]

In addition to these socioeconomic factors, results from the latest National Health Survey [18] indicate that Tasmania has higher than the national average rates for the following health risk factors: smoking $(24.9 \%)$, participating high risk alcohol consumption (13.6\%); overweight or obese $(64.0 \%)$; and participating in low levels of exercise or sedentary lifestyles $(72.1 \%)$. Data also shows that Tasmanians living outside the capital city (Hobart) are more likely to engage in these health risk behaviours [19].

The population living in the CCA region, therefore, has significant health and socioeconomic issues and were identified to benefit from targeted health promotion activities aiming to reduce health risk behaviours and increase positive lifestyle behaviours. Effective, sustainable health promotion activities, implemented at the local council level were sought to be able to address and reduce the growing disease burden resulting from these unhealthy lifestyle choices.

As such, the CCA took part in a pilot health promotion activity: the Australian Federal government's Healthy Communities Initiative (HCI). In 2011 a survey funded by the HCI was commissioned by the Tasmanian Department of Health and Human Services (DHHS) to establish baseline data concerning the barriers and enablers to the effective delivery of health promotion activities across North West Tasmania. The findings from this evaluation and feedback from the participating councils on the North West coast of Tasmania facilitated an additional two years (2011-2013) of HCI funding to further develop local capacity and respond to local community needs. This funding enabled the nine councils to conduct a variety of preventative health activities covering the topics of healthy nutrition, cooking skills and physical activity [20].

Copyright Cradle Coast Authority reproduced with permission.

These activities included programs such as:

- No Cost Gym,

- Heart Moves and Bike Education,

- Home kitchen gardening and men's cooking project,

- Cook for Life and Walkers-Talkers,

- Heart Foundation walking groups, Tai Chi and aqua fit programs,

- $\quad$ Eating Well and Outdoor Exercise,

- Workshops on community gardening, bottling and preserving, and

- $\quad$ Lift More.

In addition, a Healthy Communities Toolkit was produced to assist in building local government capacity to deliver these and other health promotion activities in the future. An additional aspect of council capacity building was the delivery of a training workshop: the Quality Improvement Program Planning System (QIPPS), to Community Development Officers from the nine councils. QIPPS was selected as a key project output, predominately as a capacity building and professional development strategy to assist participating council staff with recording and monitoring their respective HCI activities.

The HCI implemented by the nine councils within the CCA is an example of a multi-stakeholder collaborative health promotion activity taking place at the regional scale. This paper presents the perceptions of local council partners concerning the regional-scale health promotion initiative. The evaluation was undertaken as a means to establish data from which future decisions and strategies could be 
developed by the nine participating councils and provides a greater understanding of the factors influencing the processes, methods and outcomes of health promotion undertaken by local governments.

\section{Methods}

Methods used within health promotion research seek to gain and measure evidence through various qualitative and quantitative methods and there are a number of theoretical approaches that are used. These approaches include behavioural, policy, change and community development theories that seek to understand and enhance complex situations and ensure appropriate designs are in place for optimal outcomes [21-23]. However, it is also argued that there is an important role of incorporating the community's view and judgment, professional literature, systematic reviews, including standardised methodology and tools as 'evidence' for new approaches and methods in health promotion. $[24,25]$ As such, this particular approach and process was used to allow 'communities' including local councils to have greater control over planning delivering interventions that address a number of the social determinants of health. This is through improved health promotion that addresses the social, economic, and environmental factors that require national, local and community collaboration, investment and infrastructure. [26-28]

\subsection{Study Design}

The study used a mixed methods approach, which collects, analyses, and integrates quantitative and qualitative data to address the research aims and questions [29]. The rationale for this method was to better understand the experiences, challenges and positives that council partners and council members encountered concerning the regional-scale health promotion initiative in rural Tasmania [30]. The study also drew on phenomenology which is a philosophy where reality is viewed to be constructed from our own experiences and beliefs [31,32]. However, it is also a research approach in which phenomena are explored [32]. Phenomenology is the study of the everyday subjective experiences of an individual's lived world, where meaning is shaped and produced continuously [33-35]. The strengths of phenomenology strengths are in its ability to provide a "rich, in-depth understandings about social phenomena in their natural settings, which cannot be captured by quantitative methodologies." [36]

\subsection{Data Collection}

The evaluation was undertaken using a questionnaire, interviews and focus group discussions. These methods were used for collecting information concerning the capacity and attitude of the nine participating municipal councils regarding the delivery of health promotion activities within their respective communities. Research participants included representatives from a range of key stakeholder groups including staff from the nine participating councils involved in the coordination, administration or delivery of $\mathrm{HCI}$ activities (such as council General Managers, Community Development staff and associated positions); contract HCI activity providers; and leaders and representatives of the HCI governance committee. Ethical approval for the study was obtained by the Human Research Ethics Committee (Tasmania) Network prior to commencing the study.

\subsubsection{The Questionnaire}

The study adopted a questionnaire with permission from the National Heart Foundation of Australia which was developed from a review of relevant literature and piloted under the direction of the project advisory group [37]. The questionnaire gathers information about the attitudes towards the impact of the $\mathrm{HCI}$ and the role that local governments play in health promotion. It also details the level of awareness and engagement in health promotion within local governments. The questionnaire was conducted online using SurveyMonkey ${ }^{\circledR}$ with 21 questions divided into four groups: group 1 (three questions) concerned the participant's demographic characteristics, group 2 (seven questions) concerned past, current and planned health promotion initiatives, particularly those under the $\mathrm{HCI}$ funding; group 3 (six questions) related to the effectiveness of those health promotion initiatives and group 4 (three questions) were about the role of local government in health promotion (see Appendix 1- for completed questionnaire).

The link to the questionnaire was distributed to 39 potential participants via email, who were given ten days to complete it. A total of 21 responses were received (54\% response rate).

\subsubsection{Interviews and Focus Groups}

In addition to the online questionnaire, with the assistance of the CCA and the nine council managers in the North West coast of Tasmania, a convenient sample of 33 participants were recruited from the key stakeholder groups and were either interviewed $(\mathrm{n}=18)$ or participated in a focus group $(n=15)$. Information sheets, consent forms and interview schedules were provided to research participants prior to data collection. Qualitative data was also sourced from open-ended sections of the questionnaire. NVivo version 9.0 software was used for data collation, coding and analysis.

\subsection{Data Analysis}

All quantitative data from the questionnaire were coded and entered into the Statistical Packages for Social Science (SPSS) version 20, checked and explored for data integrity. In addition, descriptive statistics such as frequency and percentages were employed to analyse the results. The 
qualitative data from the interview and focus group data were transcribed, coded and analysed by one researcher using NVivo v10.0 software [38]. Each interview or focus group participant was coded based on how data was collected and then assigned a numerical code based on the order in which they participated. For example, a participant who was the fourteenth person to be interviewed in the study was given the code (IP14). For the purpose of the study, thematic analysis was used to identify recurring themes, behaviour and experience which then become a description of phenomenon. This also included newly identified or emerging themes [39]. Qualitative data was also sourced from open-ended questions from the questionnaires.

\section{Results}

A number of themes emerged from the data that included council member's perceptions of health promotion, the current health promotion priorities, the effectiveness of the health promotion initiatives, and a number of suggestions for future initiatives. Each of these themes is discussed below.

\subsection{Perceptions of Health Promotion and Current Health Promotion Priorities}

Each participant had a very clear perception of health promotion and how to translate the theory into specific actions. Although diversely articulated, many stated that they believed that health promotion was about a holistic and preventative approach to promoting a healthier life style. Health promotion was viewed as achieving a cultural shift in thinking and behaviour in the community, and it was thought that there were many different ways in which this could be implemented.

Participants were asked to list three priority health promotion initiatives that were currently being implemented by their council. These priorities were grouped into three categories: (1) initiatives to support physical activities; (2) initiatives to support healthy and safe food and; (3) other health promotion initiatives. Within the scope of health promotion activities, initiatives promoting physical activity were considered a higher priority by all nine councils, whereas healthy food and other health programs were considered a lesser priority.

\subsubsection{Initiatives to Support Physical Activities}

Overall, the response from the questionnaire regarding the provision of physical activity initiatives was positive. It was indicated by $86 \%$ of respondents that their councils currently had programs and events in place that encouraged participation in physical activity, such as Heart Foundation Walking, exercise classes, or walk to work programs; while the remaining participants indicated that these activities were either recently completed, or being developed.
Similarly, a majority (77\%) of the participants indicated that their councils currently had in place sport, recreation, and active transport infrastructure, such as recreation centres, club development, walking, cycling pathways. In addition, $85 \%$ outlined they had a physical environment that promoted physical activity, such as public open spaces, parks and green spaces.

In terms of council budgets, $46 \%$ of the participants indicated that their councils had in place a dedicated budget or specific allocation of resources for initiatives that promote physical activity and one indicated that their council was considering this for the future. Likewise, $50 \%$ indicated that their councils had in place information, education and behaviour change initiatives, such as physical activity promotion campaigns, brochures, lifestyle counselling and community awards, and one respondent indicated that this was being developed.

Only two participants indicated that their councils had planning and design initiatives; or schemes to support physical activity such as building codes for active transport, land use allocation and new development requirements, currently in place. Additionally, four respondents outlined that schemes to support physical activity were being developed or considered for the future.

\subsubsection{Initiatives to Support Safe and Healthy Food}

Beyond council initiatives to support physical activity, there was less promotion and coordination of initiatives to support healthy and safe food. For example, $46 \%$ of the participants highlighted that their councils currently had in place a dedicated budget for initiatives that supported access to healthy food; $43 \%$ had infrastructure to support healthy and safe food consumption; 58\% had a physical environment that promoted healthy and safe food production; $38 \%$ programs and events that provided healthy food options; and 46\% information, education and behaviour change initiatives related to food safety and food hygiene. Approximately one third of the respondents (31\%) indicated that their councils were currently planning, designing, or had in place regulatory initiatives to support healthy food.

\subsubsection{Other Health Promotion Initiatives}

Similar to the initiatives to promote healthy and safe food, participants indicated that other health promotion initiatives such as quit smoking programs and healthy workplace initiatives, received only moderate attention from the councils. Only $50 \%$ of the participants indicated that their councils currently had in place Healthy by Design Planning and Design Principles; 54\% outlined their councils had smoking restrictions in public places; and $50 \%$ stated their council had healthy workplace programs. One council stakeholder who completed the questionnaire indicated that their council was currently implementing or considering the implementation of 'other' health promotion initiatives such as staff-initiated health promotion programs for council 
employees.

\subsection{Effectiveness of Health Promotion Initiatives}

Each participant was asked to consider the effectiveness of any health promotion initiative that was currently being implemented or had recently been implemented. The effectiveness of the whole program was evaluated on the basis of the capacity and process assessment. The latter aimed to examine inputs (human resources, physical resources, finance, and program management), activities (delivery, monitoring and evaluation methods) and outputs of the HCI initiatives (the HCI toolkit, the application of the QIPPS, the partnerships among the nine councils, and the increased capability of local government to coordinate health promotion activities). The findings concerning the general effectiveness, successful factors and the barriers are discussed below.

\subsubsection{General Effectiveness}

Many (62\%) of the participants rated their council's health promotion initiatives as 'effective' while the remaining $38 \%$ of respondents rated them as 'just right'. In addition, the findings from the interviews and focus groups provided rich information to support the questionnaire data. Most of the participants expressed a positive view about the general effectiveness of the health promotion initiatives delivered under the $\mathrm{HCI}$.

The HCI initiatives were believed to have led to increased awareness and behaviour changes among the individuals involved, which was perceived by participants to represent a strong indicator of the program's effectiveness in terms of sustainable outcomes. Although there was no measureable evidence as to the outcomes of the HCI, its effectiveness was indicated to also be displayed through the positive attitudes of the HCI activity coordinators and their explicitly expressed eagerness to continue contributing to similar initiatives in the future.

Nevertheless, despite the prevalent positive tone, there was some acknowledgement of shortcomings of the HCI. One interview participant, whilst acknowledging the importance of community-based health promotion initiatives, did have reservations about the approach currently used to translate the objectives of the HCI funding into practice. They questioned whether the HCI funding represented " $a$ good return on investment" (IP1). It was unclear whether this was in reference to the funding level, the allocation of funds or lack of measureable outcomes from the HCI; however, this council representative suggested a more clearly-defined, coherent and coordinated approach to health promotion among all councils was needed. The interview with this participant revealed that they had doubts about the intent of the HCI funding, which had resulted in some uncertainty about the effectiveness of the HCI initiatives.

\subsubsection{Successful Features of the HCI Initiatives}

The successful features that related to the delivery of health promotion initiatives by councils that was most frequently mentioned in the questionnaire, interview and focus group participants included

- $\quad$ articipation or engagement of the target groups;

- adequate funding;

- $\quad$ support from the community and other local councils;

- $\quad$ active and engaging facilitators; and

- collaborating with other stakeholders and partners.

Other success factors included transparent and well-planned processes; professional support and advice; promotion by local media; naming of activities; matching the programs with the right community needs; and increasing awareness across council staff and councillors of health promotion in the community.

The engagement of the target groups and support from community and local councils was emphasised by a participant when they stated.

I think it worked well because they just didn't provide funding for someone to be trained to run the program, they provided the resources ... the venue and they arranged child care which is a really important part of the programs down here, so what worked well was quite holistic. (IP14)

Opportunities for creating sustainable pathways for health promotion initiatives and building local capacity were also highlighted as the key factors in the success of the initiative. The manifestations of community empowerment and community development in terms of skills, knowledge, and confidence were particularly clear when one participant commented:

It was successful as we now have trained instructors in the community, they are members of our community and ... it can be an ongoing thing. The program is up to such a point that it could be self-sustaining. (IP15)

From the perspective of the interview and focus group participants, the HCI was successful in part because it was aimed at accommodating the needs of the community. It was the inherent flexibility within the $\mathrm{HCI}$ that was widely applauded as it allowed program coordinators the scope to accommodate the needs of their respective communities.

\subsubsection{Barriers within the HCI Initiatives}

In addition the successful features of the HCI, there were a number of barriers identified by councils that hindered the successful delivery of health promotion initiatives. These included:

- a lack of funding and resources, including infrastructure and staff;

- limited funding and the risk of not being re-funded;

- a lack of engagement from the target group and communities;

- a lack of time; and

- $\quad$ arduous reporting requirements.

The most common barrier was the impact of limited funding and the risk of not being re-funded. The topic of 
financial shortage and fund depletion echoed throughout the interviews and focus groups. The lack of resources was a challenge for local government. This was highlighted by one participant who stated

It is hard, as when you have limited resources, you need to work out what you can affordably do for your community. (IP3)

The shortage of staff to dedicate to the initiatives was depicted as alarming, particularly for the smaller councils whose staff had to take on multiple roles, and thus could not devote sufficient time and energy into the initiatives. In addition, some specific programs required people with professional skills and qualifications, who were not readily available in the rural and remote communities.

Another challenge for local government was to involve or engage the target groups, most of whom were socio-economically disadvantaged:

The large focus was the low socioeconomic and unemployed and they are hard to entice into these things. (IP7)

Participants indicated that these particular target groups had their own difficulties and challenges associated with their socioeconomic disadvantage and that these might have an impact on their willingness to participate in the health promotion initiatives. It was felt the benefits of participation were not necessarily obvious to these particular target groups .

\subsection{Suggestions for Improvement}

Drawing on the factors contributing to success, as well as the barriers, the interview and focus group participants offered their suggestions about how to improve the management of health promotion initiatives in the future.

It was felt that there needed to be an element of sustainability within the process of the health promotion initiatives - that the initiative should be focussed beyond the funding timeframes. In the face of the funding limitations, a sustainable model was considered to be extremely important. Sustainability was considered integral to empowering and building capacity for the community and building on the available skills and resources in the community. It was believed that if the community was self-sustaining and has the required resources, the health promotion initiatives will continue after the closure of the funding.

In addition, to improve health promotion initiatives, there needed to be capacity to build better partnerships and communication between local governments, non-government organisations (NGOs) and service agencies, while improving the identification of the roles of all parties involved. To address this issue, participants recommended more appropriate allocation of responsibilities and tasks to allow each partner to build on their strengths and thus enhance the effectiveness of the joint initiatives.
Lastly, it was outlined that there needed to be a greater development of appropriate methods to more fully engage the target groups. To address this difficulty, it was suggested that combining resources and experiences would help develop the most appropriate methods of engagement and make participation in the initiative more attractive and accessible in different ways. Specific measures mentioned by the participants included bringing more diversity into the initiatives, avoiding initiatives of the same nature in the same community, introducing more effective strategies to communicate with the target groups, providing easy access to the initiatives, and addressing the real needs of the target groups.

\section{Discussion}

Each stakeholder had very clear perceptions regarding health promotion and how to translate the underpinning theory driving health promotion into specific on-ground actions. Health promotion was made manifest in a number of ways including awareness raising, providing access to information and services, and providing the means and skills to allow a community to actively engage in managing their own health.

What remained absent within the discussion was the evaluation of any associated environmental factors which may impact low participation rates. Additionally, discussion regarding the interventions within the social context was lacking and the need to address any underlying socioeconomic factors which may result in the low attendance of the target population.

The majority of councils had specific non-HCI funded and HCI funded health promotion programs in place that encouraged participation in physical activity; and included sport, recreation, and active transport infrastructure to support physical activity. This was reflected in the strategic plans currently including health promotion objectives, dedicated budgets, planning and design to support the initiatives. In contrast, very few councils had governance structures currently in place, such as a general council committee to oversee and coordinate health promotion initiatives.

The feedback on community involvement and collaboration with other organisations concerning health promotion was positive, while program coordination, training and guidance provided by the councils was categorised as Satisfactory or Very Good. The HCI program outputs were generally positively regarded with a strong appreciation for the value and application of the $H C I$ Toolkit, confidence in partnerships among the nine local councils; and a greater sense of the increased capability of local government to deliver health promotion activities. Still, very little feedback was obtained around the use and application of QIPPS for monitoring and evaluation of the HCI.

Evaluation responses regarding the general effectiveness 
of health promotion initiatives were relatively positive, particularly in the delivery of health promotion initiatives; however, there was very little evidence as to health improvement or behavioural changes reported. To ensure the successful delivery of future health promotion initiatives factors such as: ensuring sustainability, building better partnerships with local governments, NGOs and service agencies, and developing appropriate methods in engaging the target groups would need to be implemented. In addition, the adoption of a program delivery model based on the sharing or pooling of resources towards an agreed and common objective would need to be implemented in the future.

Though there was a reasonable response rate to the online survey $(54 \%)$, the number of participants in nine councils was small. Furthermore, some trends did emerge from the interviews and focus groups data but it was not possible to draw conclusions about the responses from these small samples. Thus, the generalizability of the findings may be limited in this regard. Additionally, this evaluation only provided baseline data for future studies. It was conducted to generally evaluate local councils' perceptions concerning a regional-scale HCI programs that were undertaken in rural areas of Tasmania, Australia, and how these programs could be improved. It was not specifically measuring which programs were working and not working, nor was its plan to use specific tools for measuring participation rates and changes in health outcomes.

\section{Conclusion}

Community based, health promotion interventions are complex and context dependent, occurring in a socio-political context where the interplay of various mechanisms influences program outcomes. Understanding this complexity can provide a basis to plan, deliver and evaluate regional community based health promotion initiatives such as the HCI, which can build capacity and provide a foundation for sustainability. Local government are suitably placed over State and Federal government concerning leadership in the delivery of health promotion initiatives, with health promotion a core business of local councils as they have the greater understanding and can affect the greatest change by investing in projects with the highest priority among those communities within their boundaries [40-42]. As such, there is a need for sustainability of health promotion initiatives beyond funding allocation and cycles, while there is capacity and a need to build and improve partnerships among local governments, NGOs and service agencies to pool resources, expertise, knowledge and capture the identified target groups within the various communities.

\section{Acknowledgements}

The project team would sincerely like to thank those individuals who graciously gave their time and input into supporting the evaluation study. This includes members from the Cradle Coast Authority; Cradle Coast Authority Healthy Communities Initiative Steering Committee; local councils and service providers who participated in the interviews and focus groups; and the senior consultant from, RhED Consulting Pty Ltd.

\section{REFERENCES}

[1] OECD. OECD Health Data 2013 - Frequently Requested Data Paris, France: Organisation for Economic Cooperation and

Development; 2013 [cited 201319 Dec]. Available from : http://www.oecd.org/health/health-systems/Table-of-Content -Metadata-OECD-Health-Data-2013.pdf.

[2] ABS. Our health risks - How do Australia compare? Canberra: Australian Bureau of Statistics; 2012 [updated 25 Setember 2012; cited 201319 December]. Available from: http://www.abs.gov.au/AUSSTATS/abs@.nsf/Lookup/4102. 0Main+Features20Jun+2012\#HOWDOWECOMPARE.

[3] World Health Organization. Global status report on noncommunicable diseases 2010. Geneva: World Health Organization, 2011.

[4] Battel-Kirk B, Barry MM, Taub A, Lysoby L. A review of the international literature on health promotion competencies: identifying frameworks and core competencies. Global Health Promotion. 2009;16(2):12-20.

[5] Keleher H, MacDougall C, Murphy B. Understanding health promotion. Melbourne: Oxford University Press; 2007.

[6] Ashton J. From healthy towns 1843 to Healthy Cities 2008. Public Health. 2009;123:e11-e3.

[7] Nutbeam D. Health promotion glossary. Health Promotion International. 1998;13(4).

[8] Easterling D, Conner R, Larson CE. Creating a healthy civic infrastructure: The legacy of the Colorado Healthy Communities Initiative. National Civic Review. 2012;101(1):35-48.

[9] Baum F, Jolley G, Hicks R, Saint K, Parker S. What makes for sustainable Healthy Cities initiatives? A review of the evidence from Noarlunga, Australia after 18 years. . Health Promotion International. 2006;21(4):259-65.

[10] Kickbusch I. Healthy Cities: a working project and a growing movement. Health Promotion International. 1989;4(2):77-82.

[11] Cradle Coast Authority. Cradle Coast Authority Burnie Cradle Coast Authority; 2013 [cited 201323 Oct]. Available from: http://www.cradlecoast.com/index.html.

[12] Cradle Coast Authority. Cradle Coast NRM, Burnie Cradle Coast Authority; 2010 [cited 201323 Oct]. Available from: http://www.cradlecoastnrm.com/region.html.

[13] ABS. 2011 Census of Population and Housing - Expanded Community Profile Canberra: Australian Bureau of Statistics; 2011 [cited 201319 December]. Available from: http://www.censusdata.abs.gov.au/census_services/getprodu ct/census/2011/communityprofile/6?opendocument\&navpos $=230$. 
[14] ABS. Socio-Economic Indexes for Areas Canberra: Australian Bureau of Statistics; 2014 [updated 23 September 2013; cited 201419 January]. Available from: http://www.abs.gov.au/websitedbs/censushome.nsf/home/sei fa?opendocument\&navpos $=260$.

[15] Department of Treasury and Finance. Long-Term Unemployment in Tasmania: A Statistical Analysis. Tasmania: Department of Treasury and Finance, 2005.

[16] Department of Treasury and Finance. Long-term unemployment - December 2011 Tasmania: Department of Treasury and Finance; 2011 [cited 2012 April 20]. Available from:

http://www.treasury.tas.gov.au/domino/dtf/dtf.nsf/LookupFil es/Long-Term-Unemployment.pdf/\$file/Long-Term-Unempl oyment.pdf.

[17] Department of Education Employment and Workplace Relations. Small area labour markets Australia - December quarter 2011 Commonwealth of Australia; 2011 [cited 2012 April 20]. Available from:

http://www.deewr.gov.au/Employment/LMI/Documents/SA LM_Dec2011.pdf

[18] ABS. National Health Survey: Summary of Results; Tasmania, 2007-2008 (Reissue) Canberra: Australian Bureau of Statistics; 2009 [updated 25 Setember 2012; cited 201319 December]. Available from:

http://www.abs.gov.au/AUSSTATS/abs@.nsf/DetailsPage/4 362.02007-2008\%20(Reissue)?Open Document.

[19] ABS. Regional Statistics, Tasmania, 2007 Canberra: Australian Bureau of Statistics; 2007 [updated 1 November 2007; cited 201319 December]. Available from: http://www.abs.gov.au/ausstats/abs@.nsf/2f762f95845417ae ca25706c00834efa/DDAD8C6B1EA90903CA257264000C AF6D?opendocument.

[20] Cradle Coast Authority. Healthy Communities Initiative Burnie: Cradle Coast Authority; 2012 [cited 2013 January 18]. Available from: http://www.cradlecoast.com/healthy_communities_initiative. html.

[21] Green J. The role of theory in evidence-based health promotion practice. Health Education Research. 2000;15(2):125-9.

[22] Linke SE, Robinson CJ, Pekmezi D. Applying Psychological Theories to Promote Healthy Lifestyles. American Journal of Lifestyle Medicine. 2013.

[23] Van den Broucke S. Theory-informed health promotion: seeing the bigger picture by looking at the details. Health Promotion International. 2012;27(2):143-7.

[24] Wong M. Evidence-based health promotion: applying it in practice. Annals of the Academy of Medicine, Singapore. 2002;31(5):656-62.

[25] Siuda K, Kaczmarek K. Evidence based health promotion. Przeglad epidemiologiczny. 2006;60(4):823-33.

[26] World Health Organization. The Jakarta Declaration on leading health promotion into the 21st century. Geneva: World Health Organization; 1997.
[27] Shareck M, Frohlich KL, Poland B. Reducing social inequities in health through settings-related interventions-a conceptual framework. Global Health Promotion. 2013;20(2):39-52.

[28] Baum F, Fisher M. Are the national preventive health initiatives likely to reduce health inequities? Australian Journal of Primary Health. 2011;17(4):320-6.

[29] Ivankova NV, Creswell JW, Stick SL. Using mixed-methods sequential explanatory design: From theory to practice. Field Methods. 2006;18(1):3-20.

[30] Tashakkori A, Creswell JW. The new era of mixed methods. Journal of Mixed Methods Research. 2007;1(1):3-7.

[31] Creswell JW. Qualitative Inquiry and Research Design: Choosing among Five Traditions. Thousand Oaks: Sage Publications; 1998.

[32] Carpenter DR. Phenomenology as Method. In: Speziale HJS, Streubert HJ, Carpenter DR, editors. Qualitative research in nursing: Advancing the humanistic imperative. 5th ed. Philadelphia: Lippincott Williams \& Wilkins; 2010.

[33] Bowling A. Research Methods in Health: Investigating Health and Health Services. 2nd ed. Berkshire: Open University Press; 2005.

[34] Liamputtong P, Ezzy D. Qualitative Research Methods. 2nd ed. South Melbourne: Oxford University Press; 2005.

[35] Greenhalgh T. Primary health care: Theory and practice. Malden: Blackwell; 2007.

[36] Wong A, Lohfeld L. Recertifying as a doctor in Canada: International Medical Graduates and the journey from entry to adaptation. Med Educ. 2008;42(1):53-60.

[37] Heart Foundation Tasmania. Review of Local Government Health Promotion Initiatives in Tasmania: Heart Foundation; 2011

[cited 201316 April]. Available from: http://www.heartfoun dation.org.au/SiteCollectionDocuments/Review $\% 20$ of $\% 20 \mathrm{~L}$ ocal $\% 20$ Government $\% 20$ Health $\% 20$ Promotion $\% 20$ final $\% 2$ 0summary\%20report\%20August\%202011.pdf

[38] QRS International. Nvivo 10.0 Melbourne: QRS International Pty Ltd; 2012. Available from: http://www.qsinternational.com/\#tab_you.

[39] Fereday J, Muir-Cochrane E. Demonstrating rigor using thematic analysis: A hybrid approach of inductive and deductive coding and theme development. International Journal of Qualitative Methods. 2008;5(1):80-92.

[40] Faguet J-P. Does decentralization increase government responsiveness to local needs?: Evidence from Bolivia. Journal of Public Economics. 2004;88(3-4):867-93.

[41] Blair T. Leading the way: A new vision for local government. London: Institute for Public Policy Research; 1998.

[42] Thomas MM, Hodge W, Smith BJ. Building capacity in local government for integrated planning to increase physical activity: evaluation of the VicHealth MetroACTIVE program. Health Promotion International. 2009;24(4):353-62. 